\title{
Author Correction: Sema7A/PlxnCl signaling triggers activity-dependent olfactory synapse formation
}

Nobuko Inoue ${ }^{1}$, Hirofumi Nishizumi ${ }^{1}$, Hiromi Naritsuka ${ }^{2}$, Hiroshi Kiyonari ${ }^{3}$ \& Hitoshi Sakano ${ }^{1}$

Correction to: Nature Communications https://doi.org/10.1038/s41467-018-04239-z, published online 9 May 2018.

The original version of this Article contained errors in Figs. 4 and 7. In Fig. 4c, the representative image of anti-GluR1-labelled PlxnC1 conditional knockout glomeruli was inadvertently replaced with a lower magnification duplicate of the equivalent image in Fig. 4a. The correct version of Fig. 4 is:

a
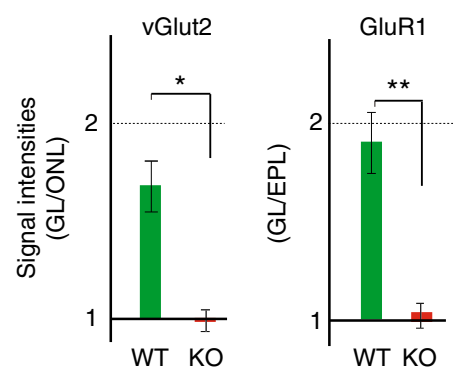

(P5)

C

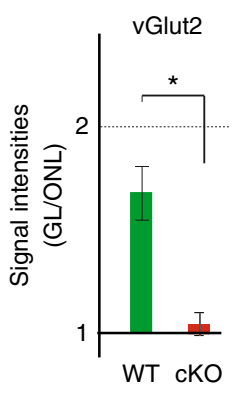

(P5)

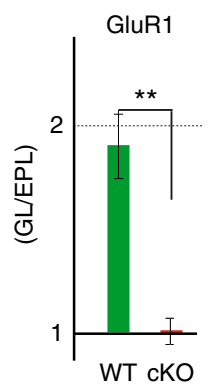

5)
Synapse formation (Sema7A KO)

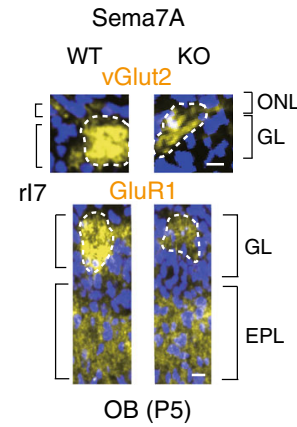

Synapse formation

(PIxnC1 cKO)

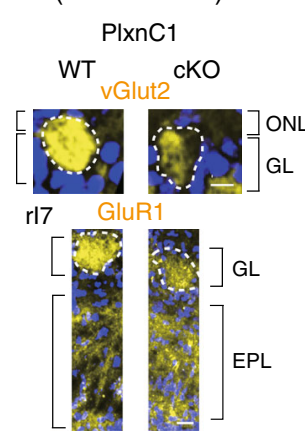

OB (P5)
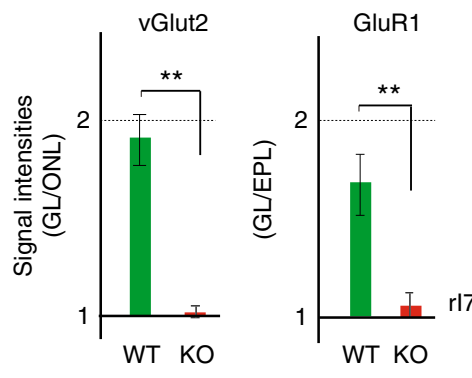

(8w)
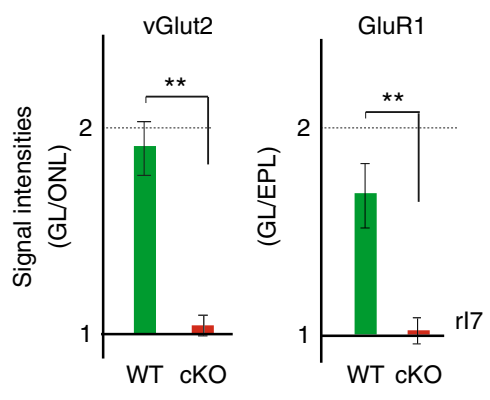

(8w) b Primary dendrite selection (Sema7A KO)

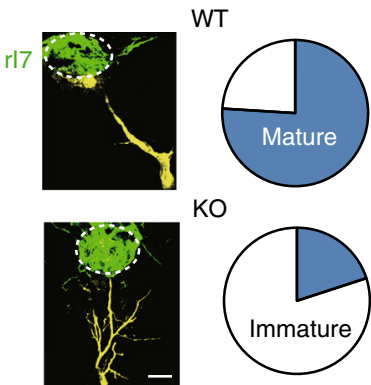

(P5)

d Primary dendrite selection (PIxnC1 cKO)

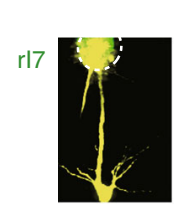

WT

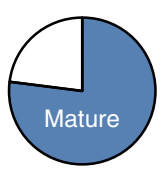

cKO
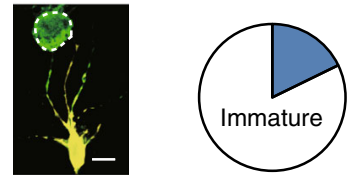

(P5)

\footnotetext{
${ }^{1}$ Department of Brain Function, University of Fukui School of Medicine, 23-3 Shimo-aizuki, Matsuoka, Fukui 910-1193, Japan. ${ }^{2}$ Department of Physiology, Graduate School of Medicine, The University of Tokyo, 7-3-1 Hongo, Bunkyo-ku, Tokyo 113-0033, Japan. ${ }^{3}$ RIKEN Institute, 2-2-3 Minatojima-minamimachi, Chuo-ku, Kobe 650-0047, Japan. Correspondence and requests for materials should be addressed to H.S. (email: sakano.hts@gmail.com)
} 
which replaces the previous incorrect version which is:

a

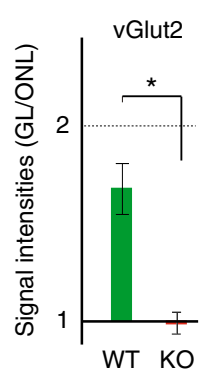

(P5)

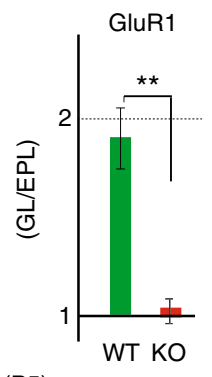

C
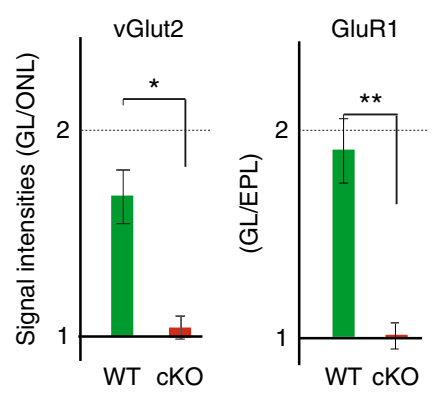

(P5)
Synapse formation

(Sema7A KO)

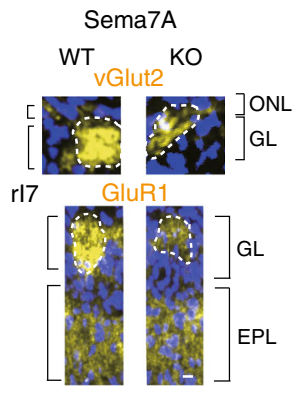

$\mathrm{OB}(\mathrm{P} 5)$

\section{Synapse formation} (PIxnC1 cKO)

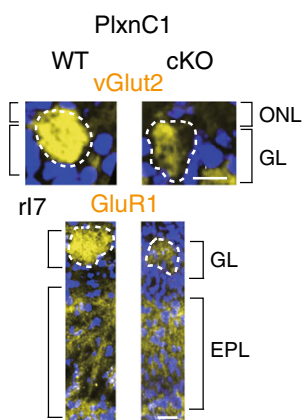

$\mathrm{OB}(\mathrm{P} 5)$

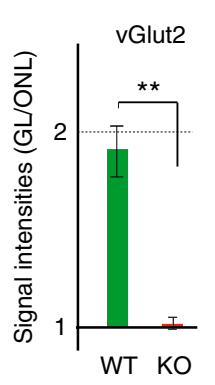

$(8 w)$
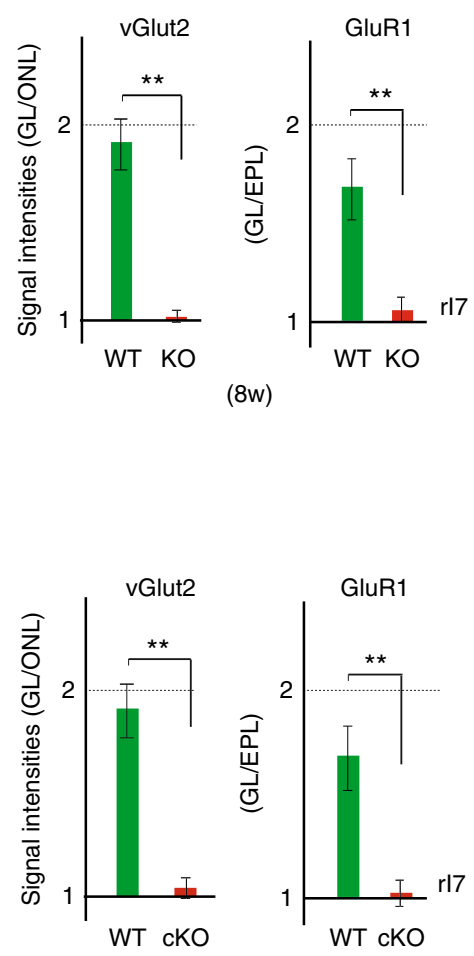

b Primary dendrite selection (Sema7A KO)

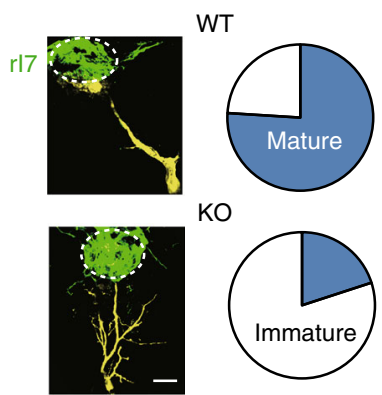

(P5)

d Primary dendrite selection (PIxnC1 cKO)

(8w)

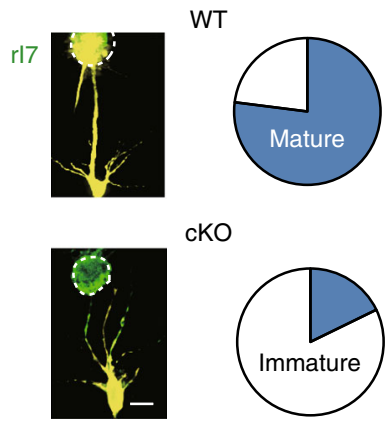

(P5)

In Fig. 7b, the representative image of myc-PlxnC1/FLAG-SAP90 expressing cells treated with Sema7A Y213S was inadvertently replaced with an inverted duplicate of the image directly above, showing cells without Sema7A treatment. The correct version of Fig. 7 is:

a

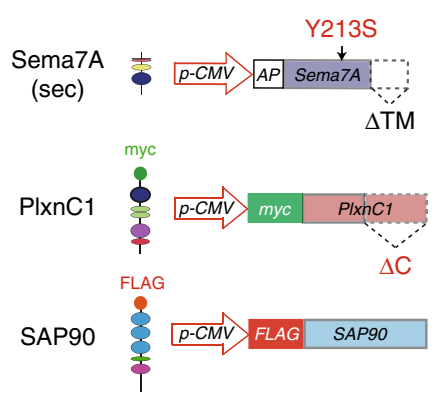

C

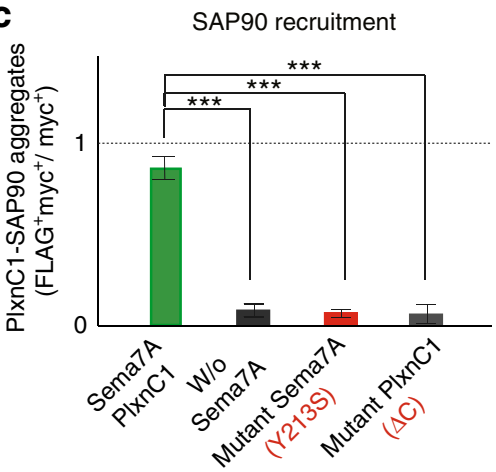

b
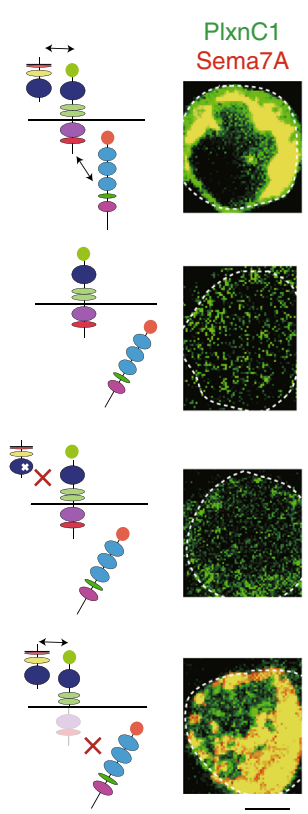

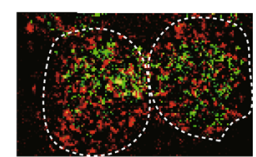

W/o

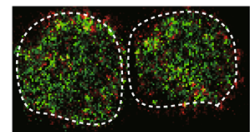

Mutant

Sema7A

(Y213S)

Sema7A

PlxnC1

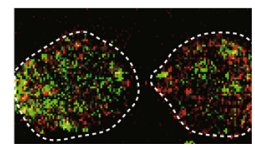

Mutant

PlxnC1

$(\Delta C)$ 
which replaces the previous incorrect version which is:

a

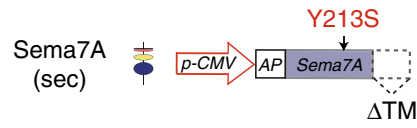

PlxnC1

SAP90
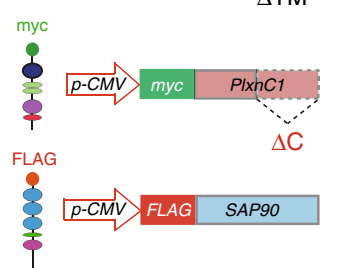

\section{C}

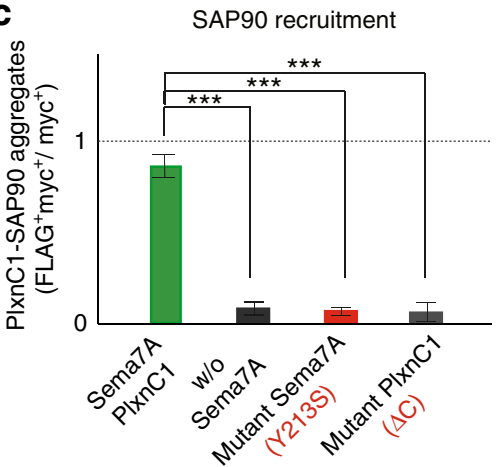

b
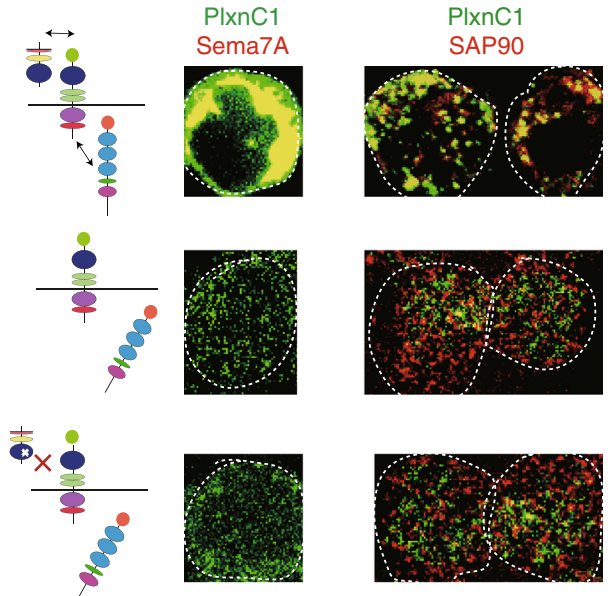

Mutant

Sema7A

(Y213S)
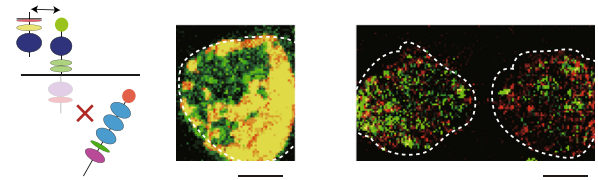

Mutant

PIxnC1

$(\Delta \mathrm{C})$

This has been corrected in both the PDF and HTML versions of the Article. Additional raw data that support the findings of these experiments can be found as Supplementary Information associated with this Correction.

Published online: 10 July 2019

(c) (1) Open Access This article is licensed under a Creative Commons Attribution 4.0 International License, which permits use, sharing, adaptation, distribution and reproduction in any medium or format, as long as you give appropriate credit to the original author(s) and the source, provide a link to the Creative Commons license, and indicate if changes were made. The images or other third party material in this article are included in the article's Creative Commons license, unless indicated otherwise in a credit line to the material. If material is not included in the article's Creative Commons license and your intended use is not permitted by statutory regulation or exceeds the permitted use, you will need to obtain permission directly from the copyright holder. To view a copy of this license, visit http://creativecommons.org/licenses/by/4.0/.

(c) The Author(s) 2019 